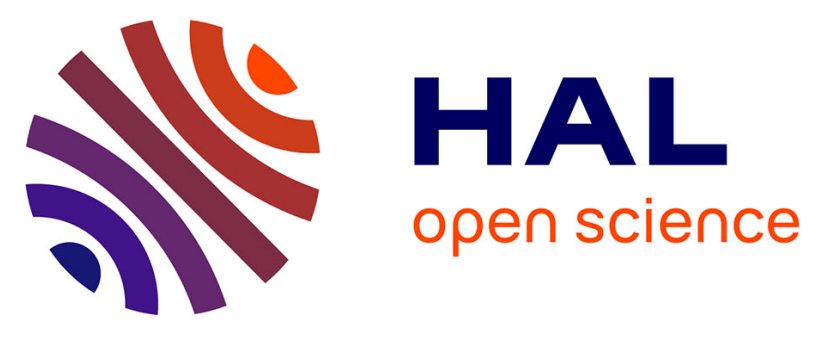

\title{
Potential strategies to prevent encrustations on urinary stents and catheters -thinking outside the box A European Network of Multidisciplinary Research to Improve Urinary Stents (ENIUS) Initiative *
}

Ali Abou-Hassan, Alexandre Barros, Noor Buchholz, Dario Carugo, Francesco Clavica, Petra de Graaf, Julia de La Cruz, Wolfgang Kram, Filipe Mergulhao, Rui Reis, et al.

\section{- To cite this version:}

Ali Abou-Hassan, Alexandre Barros, Noor Buchholz, Dario Carugo, Francesco Clavica, et al.. Potential strategies to prevent encrustations on urinary stents and catheters -thinking outside the box A European Network of Multidisciplinary Research to Improve Urinary Stents (ENIUS) Initiative *. Expert Review of Medical Devices, 2021, 10.1080/17434440.2021.1939010 . hal-03252300

\author{
HAL Id: hal-03252300 \\ https: / hal.sorbonne-universite.fr/hal-03252300
}

Submitted on 7 Jun 2021

HAL is a multi-disciplinary open access archive for the deposit and dissemination of scientific research documents, whether they are published or not. The documents may come from teaching and research institutions in France or abroad, or from public or private research centers.
L'archive ouverte pluridisciplinaire HAL, est destinée au dépôt et à la diffusion de documents scientifiques de niveau recherche, publiés ou non, émanant des établissements d'enseignement et de recherche français ou étrangers, des laboratoires publics ou privés. 


\title{
Potential strategies to prevent encrustations on urinary stents and catheters - thinking outside the box
}

\section{A European Network of Multidisciplinary Research to Improve Urinary Stents (ENIUS) Initiative*}

\begin{abstract}
Abou-Hassan $A^{1}$, Barros $A^{2}$, Buchholz $N^{3}$, Carugo $D^{4}$, Clavica $F^{5}$, De Graaf $\mathrm{P}^{6}$, De La Cruz J,7, Kram W ${ }^{3,8}$, Mergulhao $F^{9}$, Reis $\mathrm{RL}^{2}$, Skovorodkin $\mathrm{I}^{10}$, Soria Galvez $\mathrm{F}^{7}$, Zheng $\mathrm{S}^{5}$ Abou-Hassan $A^{1}$, Barros $A^{2}$, Buchholz N ${ }^{3}$, Carugo $D^{4}$, Clavica F ${ }^{5}$, De Graaf $\mathrm{P}^{6}$, De La Cruz J 3,7, Kram $\mathrm{W}^{3,8}$, Mergulhao $\mathrm{F}^{9}$, Reis $\mathrm{RL}^{2}$, Skovorodkin $\mathrm{I}^{10}$, Soria Galvez $\mathrm{F}^{7}$, Zheng $\mathrm{S}^{5}$
\end{abstract}

${ }^{1}$ Sorbonne Université, CNRS UMR 8234, PHysico-chimie des Électrolytes et Nanosystèmes InterfaciauX, F-75005 Paris, France

2 3B's Research Group, University of Minho, Barco Guimãraes, Portugal

${ }^{3}$ U-merge Research Office, London-Athens-Dubai

${ }^{4}$ Dept. of Pharmaceutics, School of Pharmacy, University College London. UK

${ }^{5}$ ARTORG Center for Biomedical Engineering Research, University of Bern, Switzerland

${ }^{6}$ Dept. of Urology, University Medical Center, Utrecht, The Netherlands

${ }^{7}$ Jesus Uson Minimally Invasive Surgery Centre Foundation. Caceres, Spain

${ }^{8}$ Dept. of Urology, University Medical Center Rostock, Germany

${ }^{9}$ Faculty of Engineering, University of Porto, Portugal

${ }^{10}$ Center for Cell Matrix Research, Faculty of Biochemistry and Molecular Medicine, University of Oulu, Finland

Running title: preventing urinary encrustations

Word count: 4593

Key words: urinary stent, encrustation, biofilm, coating, material, biosensors, antibodies, biodegradable, bacteriophages, peristalsis, surface charge

\section{Funding information:}

ENIUS is supported by the European Cooperation in Science and Technology (COST). It is a four-year project (COST action). COST is a funding organization by the European Union (EU) for the creation of research networks. 


\section{Conflict of interest:}

All authors have read and approved the content of this paper. No conflict of interest has been declared by aby of the authors.

\section{Author contribution:}

All authors have contributed to the conceptualization, referencing, content, writing, editing and proof reading of this manuscript. 


\section{Abstract}

Background: Urinary stents have been around for the last 4 decades, urinary catheters even longer. Although a lot of effort has gone into improving these devices in terms of materials, coatings and designs, they still suffer from inherent problems such as infections, encrustation, blockage, migration and patient discomfort. Research efforts have shifted onto the molecular and cellular levels, taking into consideration many aspects of the microenvironment (the physio-chemical composition of urine). The European Network of Multidisciplinary Research to Improve Urinary Stents (ENIUS) brought together European translational scientists for knowledge exchange and brainstorming towards improving urinary implants and reduce their morbidity.

Methods \& materials: The authors on this paper formed a working group within the ENIUS network tasked with assessing future research lines for the improvement of urinary implants. The topic was researched according to PRISMA. Then relevant sub-topics were addressed with a separate PRISMA search. As this was done for each individual chapter, an overall collection of search terms and PRISMA diagrams seems not practical in the framework of this paper.

Results: Sub-topics deemed relevant for urology and promising in their approach were antibody, enzyme, biomimetic, and bioactive nano-coatings, coating with antisense molecules, and coating with autologous engineered tissue. Further physico-chemical approaches such as $\mathrm{pH}$-change sensors, biodegradable metals, use of bactericidal bacteriophages and non-pathogenic competitive uropathogens, and the use of enhanced ureteric peristalsis, electrical charges and ultrasound to prevent stent encrustations.

Conclusions: All research lines addressed in this paper seem to date viable and promising. Some of them have been around for decades but have yet to proceed to clinical application (i.e. tissue engineering). Others are very recent and, at least in urology, still only conceptual (i.e. antisense molecules). Perhaps the most important learning point resulting from this panEuropean multidisciplinary effort is that collaboration between all stakeholders is not only fruitful but truly essential. 


\section{Introduction}

Urological stents and catheters are hollow tubes which maintain urinary drainage and manage obstructions [1]. They are used extensively in urology to provide a minimally invasive treatment for a wide range of indications including kidney stones, tumors, strictures and infection. They can also facilitate healing as a scaffold after injury or anastomosis, or be used as a prophylactic measure against stricture formation [2]. In modern urological practice, ureteral stents and bladder catheters, and to a lesser extent urethral and prostate stents, have become indispensable tools. Over the course of time, many improvements on designs and constitutive materials have taken place in an attempt to improve their efficacy. Nevertheless, they remain associated with several adverse effects that limit their value as tools for long-term urinary drainage. Infection, encrustation, migration, hyperplastic urothelial reaction, and patient discomfort are the most common problems $[3,4]$. Certain adverse effects can be alleviated to some extent by modifying materials and coatings [5], by changes in design $[6,7]$ and by adjusting the length and the position of the devices within the bladder [8]. However, such changes had so far elicited only limited effects.

Within the ENIUS network, a unique opportunity arose that scientists and clinicians from the whole of Europe and neighboring countries came together to discuss not only the state-ofthe-art of urinary implant research, but also to provide a unique outlook on what is on the horizon in the field. The authors of this papers formed a working group tasked to look at novel and potential research lines to improve urinary implants. As urinary stents and catheters share many similarities such as dwelling in a urinary environment, materials, flow designs, and propensity to biofilm formation and ensuing blockage, clinical and basic science research for both greatly overlap and are of relevance to each other, and consequently they have been addressed in this paper together. The first six paragraphs address novel approaches for coating catheters and stents to prevent biofilm formation, reduce friction, promote biocompatibility, and ameliorate patient tolerance. Such innovative approaches include antibody, enzyme, biomimetic, and bioactive nano-coatings, coating with antisense molecules, and coating with autologous engineered tissue. The next seven paragraphs concentrate on physico-chemical approaches such as pH-change sensors, biodegradable metals, use of bactericidal bacteriophages and non-pathogenic competitive uropathogens, and, especially for the ureter, the use of enhanced ureteric peristalsis, electrical charges and 
ultrasound waves to prevent stent encrustations. The aim of this paper is not to present yet another review on device modifications already being produced and tested, but ideas and infancy researches into novel approaches such as nanoscale or molecular technologies. It also aims to give urologists and researchers an overview of recent developments in the fields of stent and catheter related material science.

It goes without saying that a paper like this cannot provide in-depth knowledge on each topic. The interested reader is therefore encouraged to make use of the extensive reference list for further reading. 


\section{Methods \& materials}

The European Network of Multidisciplinary Research to Improve Urinary Stents (ENIUS) is a collaborative project bringing together European stakeholders in the development of urinary stents such as bioengineers, chemists, material scientists, cell biologists, medical device companies, urologists and other interested parties to exchange expertise and to brainstorm towards improving urinary implants and reducing associated morbidity. Within this framework, six working groups were tasked to assess the current state of the art in stents, computational simulation of fluid dynamics, evaluation of new stent designs, current biomaterials and coatings, and drug eluting stent technologies. The authors on this paper were tasked to assess future research lines to improve urinary stents [9].

Sub-topics were researched according to PRISMA. As this was done for each individual chapter, an overall collection of search terms and PRISMA diagrams seems not practical in the framework of this paper.

For further reading, an extensive reference list has been attached. 


\section{Antibody coated stents}

Historically, urology has been following cardiology in many aspects of stent and catheter technologies.

Antibody-coated stents developed for cardiovascular stenting focus on the mitigation of stent re-stenosis by preventing intimal proliferation and promoting early stent endothelialisation. Antibodies on the stent surface target receptors on cells responsible for these processes effectively enhancing vascularization and preventing intimal hyperplasia and thrombosis [1014]. In addition, the same stents can be designed as drug-eluting [12].

Although to our knowledge the concept of antibody coating has not yet been trialled in urology, antibodies on urinary stents and catheters could potentially capture molecules or cells that promote tissue regeneration for the repair of ureteral or urethral defects, and that provide a defensive barrier for urothelial hyperplasia and biofilm formation on polymeric and metallic stents. Firstly, components circulating in the urine that might fulfil those functions need to be identified. Then, antibodies need to be developed to bind these to the surface of the stent. Major considerations for future research are the differences between endothelium and urothelium, and between the biochemical environments in blood and urine.

\section{Enzyme coated stents}

Anti-microbial enzymes as active component of antimicrobial coatings have been utilized recently in the field of urinary catheters. These enzymes can act through various mechanisms: degrading structural components of microorganisms (hydrolytic enzymes), inducing production of antimicrobial substances in the living organism (oxidative enzymes), and preventing bacterial quorum sensing (quorum quenching enzymes) which ultimately prevent cell aggregation and production of virulent compounds [4].

In case of urinary catheters and stents, enzymes can be immobilized onto the surfaces either reversibly or irreversibly. Reversible immobilization includes methods through which the enzymes can be easily removed $[15,16]$. However, irreversible methods are generally preferred because of the improved stability and lower extent of leaching [4]. Urological trials with antimicrobial enzyme coating are still in the early stages. It was demonstrated that in vitro a cellobiose dehydrogenase $(\mathrm{CDH})$ /cellobiose stent coating inhibited several urinary pathogens including MRSA by generating $\mathrm{H}_{2} \mathrm{O}_{2}$ thus demonstrating an ability to kill microbes 
on demand when biofilms were formed [17]. Also, stent coatings with oxalate-degrading enzymes were trialed in vitro [18] and in an animal study [19]. Encrustation often results from the deposition of calcium oxalate on the biomaterial surface. A commensal colonic bacterium, oxalobacter formigenes, produces several oxalate-degrading enzymes, which, when used as a coat on silicone, resulted in an up to $53 \%$ reduction in encrustation with no apparent toxicity $[18,19]$.

Anti-microbial enzymes in urinary device coatings act therefore similarly to eluted antibiotics preventing infection and biofilm formation. Enzymes have advantages over antibiotics and other antimicrobial agents. Firstly, they are pathogen-specific, killing only specific pathogens and no other commensal bacteria. Secondly, bacterial resistance to enzymes is very rare. Antimicrobial enzymes are safer as they are natural, non-reactive and non-toxic to living organisms. However, compared to cheaper alternatives like silver and antibiotics, the production and purification of antimicrobial enzymes is expensive and they are proteins which can get denatured in extreme conditions (e.g. sterilization of device, storage and transport) [4].

\section{Biomimetic stents}

Again, cardiology research is leading the way when it comes to biomimetic stent surfaces. One would easily agree that nature's creations usually outperform man-made solutions. Therefore, researchers try to mimic biological surfaces on stents to bring them as close to the "natural thing" as possible. Biomimetic approaches are tissue-engineering tactics aiming to design materials with physical and biological properties behaving physiologically like the urinary system itself [20].

In cardiology, stenting is currently the major therapeutic treatment. However, non-biogenic metal stents are inclined to trigger a cascade of cellular and molecular events leading to restenosis and thrombosis. To overcome these problems, an endothelium-mimicking stent coating was developed allowing a rapid regeneration of a completely functioning endothelial layer [21]. Another group synthetized a novel bioinspired phospholipid copolymer. Contact angle results indicated that the coating surface rearranged to get a more hydrophilic surface at the polymer/water interface. The biomimetic coating surface resisted platelet adhesion and prolonged plasma re-calcification time significantly [22]. These are only two examples 
where biomimetic surfaces could create an ideal microenvironment to prevent re-stenosis. In addition, these surfaces can be used for drug elution as well [20].

In urology, experiments with catheter surfaces mimicking shark skin micro-patterns which have been shown to resist biofilm formation in nature [23] similarly inhibited colonization and migration of E. coli in vitro [24]. Although currently to our knowledge in urology there are no ongoing trials in either biomimetic stent composition or micro-patterns, this seems to be a promising technology. If it proves successful in cardiac stents, it will be consequently expanded to other medical devices including urinary stents and catheters.

\section{Bioactive nanocoating}

Immediately after introduction of any biomaterial into an organism, the adsorption of endogenous proteins on the surface starts with the subsequent attachment of cells controlled by this protein layer. Both protein adsorption and cell attachment are dependent not only on the chemical composition of the material surface but also its topography. Processes of cell recognition and signal transmission happen on a molecular level and can only be altered by nanotechnological structure formation processes [25]. Nanoparticle sizes < 10-15 nm and irregular particle size distribution are regarded as critical for friction, roughness and surface dislocation [26]. Polymer nano-structures offer biocompatibility, biodegradability and the option of transporting active substances [27]. Examples of biological nanostructures are lipidbased nanotubes, nanospheres and emulsions. Best known are liposomes, which form a hollow sphere into whose lumen active ingredients can be introduced. A general toxicity has not been confirmed so far [28].

In urology, kanamycin-chitosan nanoparticle coated stents showed enhanced antibacterial activity against $E$. coli and P. mirabilis in vitro [29]. Nano-structured scaffolds enhance urothelial repair function in injured rabbit bladders [30] and have been designed to replace the human urethra [31].

In future, the understanding of underlying mechanisms of the in vivo interactions between nanomaterials and cells on a molecular level will significantly advance the development of this field. Current research efforts aim at the optimization of the functionalization of implant surfaces by coating with signal molecules, such as growth factors, anti-inflammatory, or immunosuppressive substances with regards to integration and retention time. In addition, 
lab-on-a-chip applications are being developed which, for example, can detect rapidly multiresistant bacteria.

\section{Antisense molecules}

Many pathogenic pathways depend on an insufficient or, to the contrary, excess production of certain proteins [32]. More recently, antisense strategies were explored to address cancer, infectious diseases, chronic inflammatory diseases and metabolic conditions [33]. Antisense technology is a method that interferes with protein production. It can therefore be used in diseases in which the over- or under-production of a specific protein play a crucial role. The principle is that an antisense nucleic acid sequence base pairs with its complementary sense RNA strand and prevents it from being translated into a protein [32] or interferes with its functional aspects [34]. Being a target-specific approach, it is highly attractive for treating underlying molecular disease pathways [33].

Antisense technology may be used to target urinary implant contamination, infection and biofilm formation. Biofilms contain various biological macromolecules, such as extracellular polysaccharides (EPS) and nucleic acids. This EPS matrix enhances the bacterial adhesion and promotes surface accumulation and cohesion resulting in extremely structured and adherent bacterial biofilms [35]. Consequently, bacteria in biofilms are 500 to 5000 times more resistant to antibiotics $[36,37]$. Inhibition of EPS synthesis can prevent the formation of bacterial biofilms, reduce their robustness, and promote removal [38]. Especially in early stages, this strategy allows the treatment of biofilm-mediated infection through early debridement and improved efficacy of antibiotics [39].

Research linking biofilm formation with environmental signal response systems in bacteria is still in its infancy. A greater understanding of the specific genes and products whose expression and production demonstrate altered regulation in a single species (and multispecies) biofilm system is needed [40]. Biofilms on urological stents and catheters are inherent and notorious. Inhibiting biofilm formation early would overcome many associated problems and antisense technology may open a door in the future.

\section{Tissue engineering}

Since the late 1980s, stents have been implanted to prevent scar contraction mainly in the urethra but also the ureter. Longer follow-up however relativized stenting as a primary 
treatment for stricture disease [41]. Permanent stents resulted in tissue in-growth and fibrosis complicating definite surgery. Temporary stents resulted in less tissue in-growth but still fibrosis. The ideal stent is flexible, supports regeneration, reduces fibrosis, and is biodegradable. In the urethra, it should support all functions of the penis in micturition and sexual activity in a flaccid and erect state. After degradation, it should be replaced by functional autologous tissue.

Not all urethral strictures can be treated by stenting. In hypospadias, extra urethral tissue is needed for reconstruction. Tissue engineering (TE) offers a possible solution to these challenges. TE for urethral reconstruction has been studied extensively [42, 43]. Yet, clinical trials have not proceeded beyond phase 2 , and currently TE has not proceeded to clinical application. Major hurdles are tissue vascularization and tissue adaptation. In urethral strictures, frequently not only the urothelium, but also the underlying fibrotic corpus spongiosum needs to be replaced $[44,45]$.

An attractive alternative might be in vitro TE of the ureter and urethra. In this approach, naturally derived (including autologous) and/or synthetic scaffolds [46, 47], will be seeded by different types of cells in vitro. Urethral or ureteric stents could act as such scaffolds or, in turn, such scaffolds could be formed as and act like stents until the tissue has been adopted. Various types of cells of different origin, including urine-derived stem cells [48] have already been tested in preclinical trials [49]. Grafts can then be transplanted to the recipients. However, insufficient graft vascularization often leads to rejection.

Theoretically, a "single step" transplantation following an extensive in vitro graft vascularization is possible. Combining acellular scaffolds with several vascularized cell sheets to generate in vitro ready-to-use grafts might open a great potential for ureteral and urethral TE $[49,50]$. Stents and catheters can thus represent scaffolds to support the engineered tissues, or could be covered with engineered tissue to be recognized by the recipient as "own".

\section{Encrustation sensing systems}

Bladder catheters and urinary stents share indications (urinary drainage), materials, and inherent problems (infection, encrustation, biofilms, blockages etc.). Research on either is therefore relevant to the other. With bladder catheters, blockage through encrustation is a frequent problem. It often results from urine infection with urease producing organisms, 
predominantly Proteus mirabilis. Urease generates ammonium which increases urinary $\mathrm{pH}$, leading to struvite and apatite precipitation which form a crystalline biofilm that encrusts and blocks the urinary catheter. To reduce this problem, sensors have been incorporated in catheters to warn early of $\mathrm{pH}$ changes indicating impending blockage. To date, such $\mathrm{pH}$ sensors are mainly visual. A color strip indicated a risk of blockage 19 days before the actual blockage in early human trials [52]. Another indicator is a 'trigger' layer, usually EUDRAGIT ${ }^{\circledR} S$ 100 , onto a hydrogel layer encapsulating a pH reporter or antibacterial agent. Upon elevation of urinary $\mathrm{pH}$, the upper layer dissolves, triggering the release of a $\mathrm{pH}$ indicator such as carboxyfluorescein or bacteriophages. Both methods were tested in an in vitro bladder model. There was a $12 \mathrm{~h}$ advanced warning of blockage, and a 13 to $26 \mathrm{~h}$ advanced warning of delayed catheter blockage, respectively $[53,54]$. Whereas catheters have an extracorporeal part that can carry those visual indicators, stents are entirely intracorporeal. However, in the age of nano-chip technology it seems entirely possible to fix a microsensor at one or both ends of a stent transmitting $\mathrm{pH}$ values or intrarenal pressure data indicating stent obstruction wirelessly.

\section{Biodegradable metal stents}

Biodegradable metals have a great potential for temporary ureteral stents due to their favourable mechanical properties that can overcome some of the limitations associated with biodegradable polymeric ureteral stents. Therefore, the use of metallic-based biodegradable ureteral stents is a novel and promising concept.

Mg alloys were explored for their antibacterial properties (Mg-4\%Yttrium (Mg-4Y), AZ31, and commercially pure $\mathrm{Mg}$ ). There was a decrease in viable $E$. coli colonies after 3 days of culture in the presence of Mg alloys as compared to commercial polyurethane stents [55]. Pure Mg and ZK60 were studied for their in vitro corrosion in artificial urine (AU) and histocompatibility in rat bladders. ZK60 had a faster degradation both in vitro and in the rat bladders compared with pure Mg. Both metals revealed good biocompatibility during 3 weeks of implantation [56].

Another study explored the degradation of pure $\mathrm{Zn}, \mathrm{Zn}-0.5 \mathrm{Mg}, \mathrm{Zn}-1 \mathrm{Mg}, \mathrm{Zn} 0.5 \%$ aluminium (Zn-0.5Al), pure $\mathrm{Mg}$, and commercially available $\mathrm{Mg}-2 \mathrm{Zn}-1 \mathrm{Mn}$ in $\mathrm{AU}$. $\mathrm{Mg}$ and its alloy had a faster degradation when compared with Zn. However, Zn alloys and Zn-0.5Al showed a more homogeneous corrosion which represents a valuable property for biodegradable ureteral 
stent [57]. In large animal model (Guangxi Bama Minipig) for ureteral stent application, a Mg based alloy (ZJ31) showed a homogeneous stent corrosion rate, a good biocompatibility with the animal's urinary tract, and a higher antibacterial activity of ZJ31 when compared with stainless steel [58].

Even though biodegradable metal stenting in urology is a new concept and yet poorly explored, initial studies are promising.

\section{Bacteriophages}

Bacteriophages are viruses that enter bacteria, duplicate in them, and disrupt metabolic pathways of their hosts in the process. Bacteriophages destroy the bacterial cells and membranes (lytic), or duplicate in an intact bacterium (lysogenic) that then lives on. Lytic viruses can be used as antimicrobial agents. They are effective and abundantly available. Bacteriophages have a good antimicrobial selectivity and a low cell toxicity. Therefore, they have recently kindled an interest as a component of medical device coatings [4]. In the lumen of bladder catheters pre-treated with the lytic Staphylococcus epidermidis bacteriophage 456, a significant reduction of biofilm was shown [59]. Although bacteria can develop resistance to phages, a mixture of different lytic bacteriophages has been shown to be able to prevent this [60-62]. Silicone hydrogel coated bladder catheters pretreated with such phage cocktails showed significant antimicrobial activity. Therefore, mixed-species biofilms may be targeted by adapting the coating composition and mixture of phages [63]. Although the above studies all have been using bladder catheter contamination and infection as a model, the use of bacteriophages targeting biofilms on urinary stents seems promising and feasible. Bacteriophages are highly effective antimicrobial agents; and they can be incorporated into coatings of medical devices. Most importantly, in an era of ever increasing bacterial resistance to antibiotic drugs, they may be a viable alternative avoiding just that [4].

\section{Non-pathogenic bacteria}

The beneficial effects of using non-pathogenic bacteria to manage biofilm infections can be attained by different mechanisms:

i) pathogen growth inhibition by antimicrobial substances and metabolites produced by the non-pathogen

ii) competitive exclusion of pathogens by blocking adhesion sites 
iii) increased adhesion of the non-pathogen to the stent surface and subsequent inhibition of pathogen adhesion

iv) competition for nutrients

v) co-aggregation with the pathogen and

vi) modulation of the immune system.

Non-pathogenic bacteria can produce several antagonistic substances such as surfactants, bacteriocins, extracellular polymeric substances (EPS), organic acids, lactic acid, fatty acids, enzymes, and hydrogen peroxide [64], all of which can negatively affect the pathogens and/or decrease their adhesion to the stent surface. Additionally, using non-pathogenic bacteria as a live protective barrier against pathogen colonization may be advantageous because the anti-pathogen coating is self-renewable, potentially enabling a long-term activity [65].

A probiotic Escherichia coli strain Nissle 1917 forms stable biofilms on silicone surfaces particularly after modification with a biphenyl mannoside derivative. These biofilms were able to reduce the colonization by pathogenic Enterococcus faecalis for 11 days [65]. In another study, a Lactococcus lactis strain was genetically modified to produce the FimH virulence factor of uropathogenic Escherichia coli (UPEC) on the cell surface. This strain was able to form robust biofilms in abiotic surfaces and survived in the mice bladder. The protective effect against UPEC was demonstrated using a urinary tract infection (UTI) mouse model [66]. It has been shown in vivo and in vitro that Lactobacillus salivarius and its bacteriocin (salivaricin LHM) may be used as a therapeutic and prophylactic agent against Pseudomonas aeruginosa infections of the urinary tract [64]. Although these studies did not address the specific case of urological stents, the use of non-pathogenic bacteria to manage biofilm infection on these devices seems a promising strategy given the experimental conditions that were used.

\section{Preserving ureter peristalsis}

In physiological conditions, ureteral peristalsis ensures the movement of urine from the renal pelvis to the bladder in the form of boli. The insertion of an indwelling ureteral stent leads to an initial increase of peristaltic activity which is later reduced or stopped completely. Smaller stents were reported to have lower initial effects on the peristalsis. Irrespectively, eventually all types of stents do cause aperistalsis [67]. 
Despite the wide clinical application of ureteral stents, the mechanisms leading to a cessation of peristalsis are still poorly understood. There are few models [68] and studies reporting artificially triggered ureteral peristalsis:

- pharmacologically i.e. capsaicin

- mechanically i.e. applying distension

- electrical stimulation [69-71].

Peristalsis can be triggered by electrical stimulation in ex-vivo ureters with an indwelling catheter of a similar size like conventional ureteral stents. All ex-vivo ureters showed viability up to 3 hours [71]. Preserving ureteral peristalsis in stented ureters represents a potential innovative strategy against encrustation and biofilm formation on ureteral stents as it may have a 'flushing' effect on encrusted and biofilm deposits on the stent surface. In-vivo experiments would be needed to test the possibility of artificially preserving ureter peristalsis in the long term in stented ureters.

\section{Electrical charges to prevent biofilm adhesion}

Electrostatic attraction is one of the key factors influencing the initial interaction between bacteria and material surfaces. Most bacterial genera have a net negative charge and are therefore prone to attach to positively charged surfaces. Consequently, two types of engagement can be derived as antibacterial strategies, namely the material as a repellent or as a contact-killing agent. The first strategy suggests materials with high negative charge densities to be deployed as anti-bacterial stent material or coating to prevent bacterial cells from contact. Heparin, having a strong negative charge density is a potent inhibitor of encrustations and is often incorporated as a coating material in commercially available ureteral stents. However, its effectiveness to prevent biofilm is still a matter of debate [72, 73]. In contrast, the contact-killing strategy relies on a positively charged surface and a permeabilization of the bacterial cell surface that leads to the leakage of intracellular material and eventual cell death. One of the reported approaches involves grafting polyethyleneimine (PEI) [74] micro-brushes onto polyurethane (PU) stents followed by an alkylation process [75,

76]. The resulting micro-structure of PEI brushes with positive charges showed a reduction in both biofilm and encrustation in vitro and in vivo [76]. Another contact-killing agent is 
chitosan, a biopolymer with antimicrobial properties through various modes of action [77, 78]. A freeze-casting process was proposed to make entire ureteral stents out of chitosan [79]. In addition, there is an increased susceptibility of biofilm cells to antibiotics in an electric field, the "bioelectric effect" [80]. Thus, electrical charges of the stent surface seem to play a crucial role in preventing bacterial adhesion and ensuing encrustation.

\section{Ultrasound waves to prevent bacterial adhesion on urological devices}

Antimicrobial treatments based on the use of mechanical stimuli have gained increasing attention in recent years, often as an alternative (or adjuvant) to antibiotics. The use of ultrasound (US) energy is a clinically viable means to deliver mechanical stimulation within the body. Ultrasound is sound waves (often in the form of longitudinal pressure waves) with a frequency $>20^{\prime} 000 \mathrm{~Hz}$ generated from a piezoceramic transducer. Previous studies have demonstrated that US causes detachment of bacterial biofilms from material surfaces, as well as enhances delivery of antibiotics into both planktonic cells and biofilms. The mechanical action of ultrasound can be enhanced by the presence of gas microbubbles which undergo oscillations upon exposure to ultrasound waves (a process known as 'cavitation'). These bubbles form from gases dissolved in the fluid, or can be engineered for a specific application [81]. Ultrasound waves can also be transmitted along a surface (referred to as surface acoustic waves, or SAWs). It has been hypothesized that the resulting surface vibrations prevent or delay bacterial adhesion [82]. The latter approach has been employed against biofilm formation in urological catheters, and is realized by coupling the extra-corporeal segment of the catheter with piezoceramic elements, generating SAWs in the frequency range 100-300 $\mathrm{kHz}$. It has been estimated that surface oscillations can propagate over the entire surfaces of a catheter with an amplitude of 0.2-2 $\mathrm{nm}$. The effectiveness of this method in preventing biofilm development on Foley bladder catheters, both in-vitro and in a rabbit model has been evaluated. SAW-activated catheters presented a marked reduction in biofilm load in-vitro, irrespective of the bacterial strain, which was attributed to SAW-induced inhibition of bacterial surface adhesion. This effect was more prominent with lower SAW intensities (0.05$0.20 \mathrm{~mW} / \mathrm{cm}^{2}$ ). These observations were corroborated through studies in-vivo where the average number of days to development of urinary tract infection was $7.3 \pm 1.3$ days (SAWcatheter group) as opposed to $1.5 \pm 0.6$ days (non-treated group) [83]. 
Notably, a commercial SAW-activated catheter (UroShield ${ }^{\mathrm{TM}}$ ) has been developed by NanoVibronix Inc. (USA). In 2008, Zillich et al. reported on the outcome of a randomized double blinded clinical study on 22 patients, evaluating efficacy and safety of UroShield ${ }^{\mathrm{TM}}$. Catheters were deployed for an average of $\sim 9$ days, and it was concluded that patients with UroShield ${ }^{\mathrm{TM}}$ presented with lower pain and spasm levels, as well as a marked reduction in the level of biofilm formation [84]. A more recent study reported on a double blinded randomized control trial involving 55 patients, who had an indwelling urinary or suprapubic catheter for $>1$-year and had a treated UTI in the 90 days before the study. Patients were inserted UroShield $^{\mathrm{TM}}$ (or a control catheter) for 30 days. Overall, the SAW-activated UroShield ${ }^{\mathrm{TM}}$ was able to significantly reduce the bacterial load in the large majority of subjects [85]. Despite these studies demonstrating that ultrasonic SAWs can effectively prevent or delay bacterial adhesion on urological devices, to the best of the authors' knowledge this approach has not yet been tried in urological stents. The development of such a SAW-activated stent will require evaluation of technological aspects associated with the coupling and powering of the SAW source, differences in the material properties of commercial stents, and the effect of geometrical features of the stent on SAW propagation (i.e. such as side-holes and double-J ends).

\section{Conclusions}

The ENIUS network provided a unique opportunity for a multidisciplinary scientific exchange. However, it became also abundantly clear that on one hand many researchers work in isolation on a specific aspect of urological implant development and without being aware of cross-research projects or clinical implications. On the other hand, clinicians who use urinary implants daily are often not aware of the amount of research that has gone into the development of these little pieces of plastic. Addressing various aspects of research and developments in the field was truly an eye opener for all stakeholders. Therefore, this paper hopefully will enable them to consider various research approaches for the same problems and open ways for collaboration and cross-thinking.

Up to date, most of urological implant research was focusing on structural and material improvements (which is still ongoing) but it is fascinating to see the shift towards cellular, 
molecular and micro-environmental approaches, the latter encompassing external proteins, antibodies, enzymes, competing bacteria and viruses.

All approaches listed in this paper seem viable and promising. Some of them have been around for decades but have not proceeded to clinical application (i.e. tissue engineering) and others are very recent and, at least in urology, still only conceptual (i.e. antisense molecules). Perhaps the most important conclusion resulting from this pan-European multidisciplinary effort is that collaboration between all stakeholders is not only fruitful but essential. 


\section{References}

1. Atala A. Engineering organs. Curr Opin Biotechnol. 2009;20(5):575-592.

2. Borin JF, Melamud O, Clayman RV. Initial experience with full-length metal stent to relieve malignant ureteral obstruction. J Endourol. 2006;20(5):300-304.

3. Dyer RB, Chen MY, Zagoria RJ, Regan JD, Hood CG, Kavanagh PV. Complications of ureteral stent placement. Radiographics. 2002;22(5):1005-1022.

4. Singha P, Locklin J, Handa $\mathrm{H}$. A review of the recent advances in antimicrobial coatings for urinary catheters. Acta Biomater. 2017;50:20-40.

5. Kram W, Rebl H, Wyrwa R, Laube T, Zimpfer A, Maruschke M, Frank M, Vollmar B, Kundt G, Schnabelrauch M, Nebe B, Buchholz N, Hakenberg OW. Paclitaxel-coated stents to prevent hyperplastic proliferation of ureteral tissue: from in vitro to in vivo. Urolithiasis. 2020 Feb;48(1):47-56.

6. Wiseman O, Ventimiglia E, Doizi S, Kleinclauss F, Letendre J, Cloutier J, Traxer O. Effects of Silicone Hydrocoated Double Loop Ureteral Stent on Symptoms and Quality of Life in Patients Undergoing Flexible Ureteroscopy for Kidney Stone: A Randomized Multicenter Clinical Study. J Urol. 2020 Oct;204(4):769-777.

7. Maan Z, Patel D, Moraitis K, El-Husseiny T, Papatsoris AG, Buchholz NP, Masood J. Comparison of stent-related symptoms between conventional Double-J stents and a new-generation thermoexpandable segmental metallic stent: a validated-questionnaire-based study. J Endourol. 2010 Apr;24(4):589-93.

8. Inn FX, Ahmed N, Hou LG, Abidin ZAZ, Yi LL, Zainuddin ZM. Intravesical stent position as a predictor of quality of life in patients with indwelling ureteral stent. Int Urol Nephrol. 2019 Nov;51(11):1949-1953.

9. www.enius.org (last accessed $18^{\text {th }}$ March 2021)

10. Wawrzyńska M, Duda M, Wysokińska E, Strządała L, Biały D, Ulatowska-Jarża A, Kałas W, Kraszewski S, Pasławski R, Biernat P, Pasławska U, Zielonka A, Podbielska H, Kopaczyńska M. Functionalized CD133 antibody coated stent surface simultaneously promotes EPCs adhesion and inhibits smooth muscle cell proliferation-A novel approach to prevent in-stent restenosis. Colloids Surf B Biointerfaces. 2019;174(1): 587-597.

11. Wawrzyńska M, Kraskiewicz $H$, Paprocka M, Krawczenko A, Bielawska-Pohl A, Biały D, Roleder T, Wojakowski W, O'Connor IB, Duda M, Michal R, Wasyluk $\measuredangle$, Plesch G, Podbielska H, Kopaczyńska M, Wall JG. Functionalization with a VEGFR2-binding antibody fragment leads to enhanced endothelialization of a cardiovascular stent in vitro and in vivo. J Biomed Mater Res B Appl Biomater. 2020; 108(1):213-224.

12. de Winter RJ, Chandrasekhar J, Kalkman DN, Aquino MB, Woudstra P, Beijk MA, Sartori S, Baber U, Tijssen JG, Koch KT, Dangas GD, Colombo A, Mehran R; MASCOT; REMEDEE Registry Investigators. 1-Year Clinical Outcomes of All-Comer Patients Treated With the Dual-Therapy COMBO Stent: Primary Results of the COMBO Collaboration. JACC Cardiovasc Interv. 2018;11(19):1969-1978.

13. Cui S, Liu JH, Song XT, Ma GL, Du BJ, Lv SZ, Meng L, Gao QS, Li K. A novel stent coated with antibodies to endoglin inhibits neointimal formation of porcine coronary arteries. Biomed Res Int. 2014; 2014:428619.

14. Lim KS, Jeong MH, Bae IH, Park JK, Park DS, Kim JM, Kim JH, Kim HS, Kim YS, Jeong HY, Song SJ, Yang EJ, Cho DL, Sim DS, Park KH, Hong YJ, Ahn Y. Effect of polymer-free TiO2 stent coated 
with abciximab or alpha lipoic acid in porcine coronary restenosis model. J Cardiol. 2014;64(5):409-418.

15. Cabral J, Novais J, Kennedy J. Immobilization studies of whole microbial cells on transition metal activated inorganic supports. Appl Microbiol Biotech. 1986; 23(3-4):157- 162.

16. Roig M. Immobilised cells and enzymes-A practical approach: Edited by J Woodward. pp 177. IRL Press, Oxford. 1985. ISBN-947946-21-7.

17. Thallinger B, Argirova M, Lesseva M, Ludwig R, Sygmund C, Schlick A, Nyanhongo GS, Guebitz GM. Preventing microbial colonisation of catheters: antimicrobial and antibiofilm activities of cellobiose dehydrogenase. Int J Antimicrob Agents. 2014; 44(5): 402-408.

18. Malpass CA, Millsap KW, Sidhu H, Gower LB. Immobilization of an oxalate-degrading enzyme on silicone elastomer. J Biomed Mater Res. 2002;63(6): 822-829.

19. Watterson JD, Cadieux PA, Beiko DT, Cook AJ, Burton JP, Harbottle RR, Lee C, Rowe E, Sidhu $H$, Reid G, Denstedt JD. Oxalate-degrading enzymes from Oxalobacter formigenes: a novel device coating to reduce urinary tract biomaterial-related encrustation. J Endourol. 2003 Jun;17(5):269-274.

20. Elsawy MM, de Mel A. Biofabrication and biomaterials for urinary tract reconstruction. Res Rep Urol. 2017; 9:79-92.

21. Yang Y, Gao P, Wang J, Tu Q, Bai L, Xiong K, Qiu H, Zhao X, Maitz MF, Wang H, Li X, Zhao Q, Xiao $Y$, Huang N, Yang Z. Endothelium-Mimicking Multifunctional Coating Modified Cardiovascular Stents via a Stepwise Metal-Catechol-(Amine) Surface Engineering Strategy. AAAS Research. 2020; Article ID 9203906.

22. Fan D, Jia Z, Yan X, Liu X, Dong W, Sun F, Ji J, Xu J, Ren K, Chen W, Shen J, Qiu H, Gao R. Pilot study of a cell membrane like biomimetic drug-eluting coronary stent]. Sheng wu yi xue Gong Cheng xue za zhi. 2007; 24(3):599-602.

23. Reddy ST, Chung KK, McDaniel CJ, Darouiche RO, Landman J, Brennan AB. Micropatterned surfaces for reducing the risk of catheter-associated urinary tract infection: an in vitro study on the effect of sharklet micropatterned surfaces to inhibit bacterial colonization and migration of uropathogenic Escherichia coli. J Endourol. 2011 Sep;25(9):1547-52.

24. Schumacher JF, Carman ML, Estes TG, Feinberg AW, Wilson LH, Callow ME, Callow JA, Finlay $J A$, Brennan AB. Engineered antifouling microtopographies - effect of feature size, geometry, and roughness on settlement of zoospores of the green alga Ulva. Biofouling. 2007;23(1-2):5562.

25. Webster TJ, Ahn ES. Nanostructured Biomaterials for Tissue Engineering Bone. In: Tissue Engineering II: Basics of Tissue Engineering and Tissue Applications. Lee K, Kaplan D (eds) 2007, Springer Berlin Heidelberg: Berlin, Heidelberg. p. 275-308.

26. Rane GK, Welzel U, Meka SR, Mittemeijer EJ. Non-monotonic lattice parameter variation with crystallite size in nanocrystalline solids. Acta Materialia, 2013. 61(12): 4524-4533.

27. Jaggessar A, Shahali H, Mathew A, Yarlagadda PKDV. Bio-mimicking nano and microstructured surface fabrication for antibacterial properties in medical implants. J Nanobiotechnology. 2017;15(1):64.

28. Raja IS, Song SJ, Kang MS, et al. Toxicity of Zero- and One-Dimensional Carbon Nanomaterials. Nanomaterials (Basel). 2019;9(9):1214.

29. Venkat Kumar G, Su CH, Velusamy P. Surface immobilization of kanamycin-chitosan nanoparticles on polyurethane ureteral stents to prevent bacterial adhesion. Biofouling. 2016 Sep 13;32(8):861-70. 
30. Ling $Q$, Wang T, Yu X, Wang SG, Ye ZQ, Liu JH, Yang SW, Zhu XB, Yu J. UC-VEGF-SMC Three Dimensional (3D) Nano Scaffolds Exhibits Good Repair Function in Bladder Damage. J Biomed Nanotechnol. 2017 Mar;13(3):313-23.

31. Wang Z, Hu J, Yu J, Chen D. Preparation and Characterization of Nano-Laponite/PLGA Composite Scaffolds for Urethra Tissue Engineering. Mol Biotechnol. 2020 Mar;62(3):192-199.

32. Gupta S, Singh RP, Rabadia N, Patel G, Panchal H. Antisense technology. Int J Pharm Sci Rev Res. 2011; 9,2: 38-45.

33. Potaczek DP, Garn H, Unger SD, Renz H. Antisense molecules: A new class of drugs. J Allergy Clin Immunol. 2016; 137,5: 1334-1346.

34. Goodchild J. Oligonucleotide therapeutics: 25 years agrowing. Curr Opin Mol Ther. 2004; 6: 120-128.

35. Hall-Stoodley L, Costerton JW, Stoodley P. Bacterial biofilms: from the natural environment to infectious diseases. Nat Rev Microbiol. 2004; 2(2): 95-108.

36. Costerton JW, Stewart PS, Greenberg EP. Bacterial biofilms: a common cause of persistent infections. Science. 1999; 284(5418): 1318-1322.

37. Neethirajan S, Clond MA, Vogt A. Medical biofilms-nanotechnology approaches. J Biomed Nanotechnol. 2014; 10(10): 2806-2827.

38. Tursi SA, Tukel C. Curli-containing enteric biofilms inside and out: matrix composition, immune recognition, and disease implications. Microbiol Mol Bio Rev. 2018; 82(4), e00028-18.

39. Zhang K, Li X, Yu C, Wang Y. Promising Therapeutic Strategies Against Microbial Biofilm Challenges. Front Cell Infect Microbiol. 2020;10: 359.

40. Shirtliff ME, Mader JT, Camper AK. Molecular Interactions in Biofilms. Chem Biol. 2002; 9: 859871.

41. Djordjevic ML. Treatment of urethral stricture disease by internal urethrotomy, dilatation, or stenting. Europ Urol Suppl. 2016;15(1):7-12.

42. de Kemp V, de Graaf P, Fledderus JO, Ruud Bosch JL, de Kort LM. Tissue engineering for human urethral reconstruction: systematic review of recent literature. PLoS One. 2015;10(2):e0118653.

43. Versteegden LRM, de Jonge PKJD, IntHout J, van Kuppevelt TH, Oosterwijk E, Feitz WFJ, de Vries RBM, Daamen WF. Tissue Engineering of the Urethra: A Systematic Review and Metaanalysis of Preclinical and Clinical Studies. Eur Urol. 2017;72(4):594-606.

44. Ram-Liebig G, Barbagli G, Heidenreich A, Fahlenkamp D, Romano G, Rebmann U, Standhaft D, van Ahlen $\mathrm{H}$, Schakaki S, Balsmeyer U, Spiegler M, Knispel H. Results of Use of TissueEngineered Autologous Oral Mucosa Graft for Urethral Reconstruction: A Multicenter, Prospective, Observational Trial. EBioMedicine. 2017;23:185-192.

45. de Graaf P, Ramadan R, Linssen EC, Staller NA, Hendrickx APA, Pigot GLS, Meuleman EJH, Bouman M, Özer M, Bosch JLHR, de Kort LMO. The multilayered structure of the human corpus spongiosum. Histol Histopathol. 2018;33(12):1335-1345.

46. Wissing TB, Bonito V, Bouten CVC, Smits AIPM. Biomaterial-driven in situ cardiovascular tissue engineering-a multi-disciplinary perspective. NPJ Regen Med. 2017 Jun 16;2:18. doi: 10.1038/s41536-017-0023-2. PMID: 29302354; PMCID: PMC5677971. 
47. Setayeshmehr M, Esfandiari E, Rafieinia M, Hashemibeni B, Taheri-Kafrani A, Samadikuchaksaraei A, Kaplan DL, Moroni L, Joghataei MT. Hybrid and Composite Scaffolds Based on Extracellular Matrices for Cartilage Tissue Engineering. Tissue Eng Part B Rev. 2019;25(3):202-224.

48. Chapple C. Tissue engineering of the urethra: where are we in 2019? World J Urol. 2020;38(9):2101-2105.

49. Sakaguchi K, Shimizu T, Horaguchi S, Sekine H, Yamato M, Umezu M, Okano T. In vitro engineering of vascularized tissue surrogates. Sci Rep. 2013;3:1316.

50. Sekiya S, Shimizu T. Introduction of vasculature in engineered three-dimensional tissue. Inflamm Regen. 2017;37:25.

51. Little MH. Regrow or repair: potential regenerative therapies for the kidney. J Am Soc Nephrol. 2006;17(9):2390-2401.

52. Malic S, Waters MG, Basil L, Stickler DJ, Williams DW. Development of an "early warning" sensor for encrustation of urinary catheters following Proteus infection. J Biomed Mater Res B Appl Biomater. 2012;100(1):133-137.

53. Milo S, Thet NT, Liu D, Nzakizwanayo J, Jones BV, Jenkins ATA. An in-situ infection detection sensor coating for urinary catheters. Biosens Bioelectron. 2016;81:166-172.

54. Milo S, Hathaway H, Nzakizwanayo J , Alves DR, Esteban PP, Jones BV, Jenkins ATA . Prevention of encrustation and blockage of urinary catheters by Proteus mirabilis via $\mathrm{pH}$ triggered release of bacteriophage. J Mater Chem B. 2017;5(27):5403-5411.

55. Lock JY, Wyatt E, Upadhyayula S, Whall A, Nuñez V, Vullev VI, Liu H. Degradation and antibacterial properties of magnesium alloys in artificial urine for potential resorbable ureteral stent applications. J Biomed Mater Res A. 2014;102(3):781-792.

56. Zhang S, Bi Y, Li J, Wang Z, Yan J, Song J, Sheng H, Guo H, Li Y. Biodegradation behavior of magnesium and ZK60 alloy in artificial urine and rat models. Bioact Mater. 2017;2(2):53-62.

57. Champagne S, Mostaed E, Safizadeh F, Ghali E, Vedani M, Hermawan H. In Vitro Degradation of Absorbable Zinc Alloys in Artificial Urine. Materials (Basel). 2019;12(2):295.

58. Tie D, Liu H, Guan R, Holt-Torres P, Liu Y, Wang Y, Hort N. In vivo assessment of biodegradable magnesium alloy ureteral stents in a pig model. Acta Biomater. 2020;116:415-425.

59. Curtin JJ, Donlan RM. Using Bacteriophages to Reduce Formation of Catheter-Associated Biofilms by Staphylococcus epidermidis. Antimicrob Agents and Chemother. 2006; 50(4): 1268-1275.

60. Carson L, Gorman SP, Gilmore BF. The use of lytic bacteriophages in the prevention and eradication of biofilms of Proteus mirabilis and Escherichia coli. FEMS Immunology \& Medical Microbiology. 2010; 59(3):447-455.

61. Fu W, Forster T, Mayer O, Curtin JJ, Lehman SM, Donlan RM. Bacteriophage Cocktail for the Prevention of Biofilm Formation by Pseudomonas aeruginosa on Catheters in an In Vitro Model System. Antimicrob Agents and Chemother. 2010; 54(1):397-404.

62. Liao KS, Lehman SM, Tweardy DJ, Donlan RM, Trautner BW. Bacteriophages are synergistic with bacterial interference for the prevention of Pseudomonas aeruginosa biofilm formation on urinary catheters. J Appl Microbiol. 2012; 113(6):1530-1539.

63. Lehman SM, Donlan RM. Bacteriophage-mediated control of a two-species biofilm formed by microorganisms causing catheter-associated urinary tract infections in an in vitro urinary catheter model. Antimicrob Agents Chemother. 2015; 59(2):1127-1137. 
64. Mahdi LH, Jabbar HS, Auda IG. Antibacterial immunomodulatory and antibiofilm triple effect of Salivaricin LHM against Pseudomonas aeruginosa urinary tract infection model. Int J Biol Macromol. 2019; 134:1132-1144.

65. Chen Q, Zhu Z, Wang J, Lopez Al, Li S, Kumar A, Yu F, Chen H, Cai C, Zhang L. Probiotic E. coli Nissle 1917 biofilms on silicone substrates for bacterial interference against pathogen colonization. Acta Biomater. 2017; 50:353-360.

66. Derakhshandeh S, Shahrokhi N, Khalaj V, Habibi M, Moazzezy N, Karam MRA, Bouzari S. Surface display of uropathogenic Escherichia coli FimH in Lactococcus lactis: In vitro characterization of recombinant bacteria and its protectivity in animal model. Microb Pathogenesis. 2020; 141: 103974

67. Venkatesh R, Landman J, Minor SD, Lee DI, Rehman J, Vanlangendonck R, Ragab M, Morrissey $\mathrm{K}$, Sundaram CP, Clayman RV. Impact of a double-pigtail stent on ureteral peristalsis in the porcine model: initial studies using a novel implantable magnetic sensor. J Endourol. 2005;19(2):170-176.

68. van Duyl WA. Theory of propagation of peristaltic waves along ureter and their simulation in electronic model. Urology. 1984;24(5):511-520.

69. Teele ME, Lang RJ. Stretch-evoked inhibition of spontaneous migrating contractions in a whole mount preparation of the guinea-pig upper urinary tract. Br J Pharmacol. 1998;123(6):11431153.

70. van Mastrigt R, Tauecchio EA. Bolus propagation in pig ureter in vitro. Urology. 1984;23(2):157-162.

71. Haeberlin A, Schürch K, Niederhauser T, Sweda R, Schneider MP, Obrist D, Burkhard F, Clavica F. Cardiac electrophysiology catheters for electrophysiological assessments of the lower urinary tract-A proof of concept ex vivo study in viable ureters. Neurourol Urodyn. 2019;38(1):87-96.

72. Lange $\mathrm{D}$, Elwood $\mathrm{CN}$, Choi K, Hendlin K, Monga M, Chew BH. Uropathogen interaction with the surface of urological stents using different surface properties. J Urol. 2009;182(3):1194-1200.

73. Rebl H, Renner J, Kram W, Springer A, Fritsch N, Hansmann H, Hakenberg OW, Nebe JB. Prevention of Encrustation on Ureteral Stents: Which Surface Parameters Provide Guidance for the Development of Novel Stent Materials? Polymers (Basel). 2020;12(3):558.

74. Lan $T$, Guo $Q$, Shen X. Polyethyleneimine and quaternized ammonium polyethyleneimine: the versatile materials for combating bacteria and biofilms. J Biomater Sci Polym Ed. 2019;30(14):1243-1259.

75. Gultekinoglu M, Tunc Sarisozen Y, Erdogdu C, Sagiroglu M, Aksoy EA, Oh YJ, Hinterdorfer P, Ulubayram K. Designing of dynamic polyethyleneimine (PEI) brushes on polyurethane (PU) ureteral stents to prevent infections. Acta Biomater. 2015;21:44-54.

76. Gultekinoglu M, Kurum B, Karahan S, Kart D, Sagiroglu M, Ertaş N, Haluk Ozen A, Ulubayram K. Polyethyleneimine brushes effectively inhibit encrustation on polyurethane ureteral stents both in dynamic bioreactor and in vivo. Mater Sci Eng C Mater Biol Appl. 2017;71:1166-1174.

77. Verlee A, Mincke S, Stevens CV. Recent developments in antibacterial and antifungal chitosan and its derivatives. Carbohydr Polym. 2017;164:268-283.

78. Chang A, Frias R, Alvarez L, Bigol U, Guzman J. Comparative antibacterial activity of commercial chitosan and chitosan extracted from Auricularia sp. Biocatal Agric Biotechnol. 2019;17:189-195. 
79. Yin K, Divakar P, Wegst UGK. Freeze-casting porous chitosan ureteral stents for improved drainage. Acta Biomater. 2019;84:231-241.

80. Stoodley P, deBeer D, Lappin-Scott HM. Influence of electric fields and $\mathrm{pH}$ on biofilm structure as related to the bioelectric effect. Antimicrob Agents Chemother. 1997 Sep;41(9):1876-9.

81. LuTheryn G, Glynne-Jones P, Webb JS, Carugo D. Ultrasound-mediated therapies for the treatment of biofilms in chronic wounds: a review of present knowledge. Microb Biotechnol. 2020; 13(3):613-628.

82. Wang H, Teng F, Yang X, Guo X, Tu J, Zhang C, Zhang D. Preventing microbial biofilms on catheter tubes using ultrasonic guided waves. Sci Rep. 2017; 7:616.

83. Hazan Z, Zumeris J, Jacob H, Raskin H, Kratysh G, Vishnia M, Dror N, Barliya T, Mandel M, Lavie G. Effective Prevention of Microbial Biofilm Formation on Medical Devices by Low-Energy Surface Acoustic Waves. Antimicrob Agents Chemother. 2006; 50(12):4144.

84. Simon Z, Weber C, Ikinger U. Biofilm Prevention By Surface Acoustic Waves: A New Approach To Urinary Tract Infections - A Randomized, Double Blinded Clinical Study. A report by NanoVibronix. Document: NV-US-WP-001. 2008.

85. Markowitz S, Rosenblum J, Goldstein M, Gadagkar HP, Litman L. The Effect of Surface Acoustic Waves on Bacterial Load and Preventing Catheter- associated Urinary Tract Infections (CAUTI) in Long Term Indwelling Catheters. Med Surg Urol. 2018; 7(4):1000210. 